\title{
Benchmark of a forging process with a hammer: comparison between fem simulation results and real part shapes using 3D digitising scanner
}

\author{
Carl Labergère ${ }^{1, a}$, Sébastien Remy ${ }^{1}$, Pascal Lafon ${ }^{1}$, Arnaud Delespierre ${ }^{2}$, \\ LAURENT DANIEL ${ }^{1}$ AND GaO Kang ${ }^{1}$ \\ 1 University of Technology of Troyes, ICD/LASMIS, UMR STMR 6279, 12 rue Marie Curie, BP 2060, 10010 Troyes, France \\ 2 Estamfor, Design and Process, 32 rue de l'Espérance, BP 27, 08800 Les Hautes Rivières, France
}

Received 3 May 2011, Accepted 23 May 2011

\begin{abstract}
As 3D scanners and numerical simulation are now mature, we have made a benchmark by comparing simulation results with real forged parts. We did consider the complete forging process of a cylindrical part using hammer from the billet to the final part. This process has been simulated using a thermo-elasto-viscoplastic constitutive equation including the ductile damage with the implemented with the help of VUMAT subroutine provided by ABAQUS software. Before and after each step, the forged part is scanned and compared with the result of the FEM simulation in order to tune some of the process numerical simulation parameters.
\end{abstract}

Key words: Numerical simulation / FEM / thermo-elasto-viscoplasticity / ductile damage / 3D scanning / forging

Résumé - Benchmark d'une gamme de forgeage par matériau pilon. Comparaison entre pièces réelles numérisées en $3 \mathrm{D}$ et pièces virtuelles modélisées par MEF. La numérisation par scanner $3 \mathrm{D}$ et la simulation numérique des procédés sont actuellement des outils robustes en progrès croissant. Nous proposons dans cet article un benchmark de forgeage d'une pièce cylindrique par marteau pilon avec une gamme complète (écrasement+estampage). Pour chaque frappe, nous avons numérisé le lopin déformé avec un bras Romer équipé d'une tête laser. Parallèlement, les opérations de la gamme ont été simulées avec un modèle de comportement thermo-élasto-viscoplastique endommageable intégré dans le logiciel ABAQUS avec remaillage adaptatif. Les nuages de points 3D obtenus ont été ensuite comparés aux formes des différents lopins obtenues par la simulation numérique afin d'ajuster certains paramètres de la simulation du procédé.

Mots clés : Simulation numérique / MEF / thermo-visco-plasticité / endommagement / numérisation 3D / forgeage

\section{Introduction}

In most companies, metal-forming processes need accurate expert knowledge in order to be set up. Nowadays, design of metal-forming tools is done with computer aided software applications (CAX). Within these applications, finite-elements approach enables the simulation of the process. This simulation needs a model that includes many parameters (material behaviour, nature of the contact, mesh... ) [1-17]. Most of the time, to measure the value of some of these parameters, experimentations are driven. The fact is that other parameters cannot be measured (internal temperature, friction level...) as for the

${ }^{a}$ Corresponding author: carl.labergere@utt.fr hot forging process $[1-3,5,6,8,14,15,17]$. Accordingly, it can be expected that some of those parameters can be deduced from the geometry of the part. One option is to use 3D digitising technologies associated with appropriate technique of surface reconstruction that are today very accessible. They bring an excellent compromise accuracy/efficiency of measurement. In this paper, we will describe the usage of a 3D laser scanner in order to obtain the geometry of the part in order to tune some of the parameters of numerical simulation of a forging process.

This paper proposes a benchmark of the forging of a cylindrical part using a hammer. The complete process includes a platting operation and a stamping operation using forming tools. For each blow, we have digitised the $3 \mathrm{D}$ shape changed part with a Romer 3D 


\section{Nomenclature}

\begin{tabular}{|ll|}
\hline$\underline{\underline{\alpha}}$ & Elastic properties tensor \\
$\underline{\underline{\varepsilon}}$ & Cauchy stress tensor \\
$\underline{\mathrm{X}}$ & Elastic strain tensor \\
$\underline{\alpha}$ & Kinematic hardening stress tensor \\
$R$ & Isotropic hardening stress \\
$r$ & Isotropic hardening strain \\
$R_{\mathrm{c}}$ & Isotropic dynamic recrystallisation stress \\
$r_{\mathrm{c}}$ & Isotropic dynamic recrystallisation strain \\
$D$ & Isotropic ductile damage \\
$Y$ & Thermodynamic damage force \\
$\sigma_{\mathrm{I}}$ & Major principal stress \\
$\sigma_{\mathrm{II}}$ & Middle principal stress \\
$\sigma_{\mathrm{III}}$ & Minor principal stress \\
$\sigma_{y}$ & limit yield stress \\
\hline
\end{tabular}

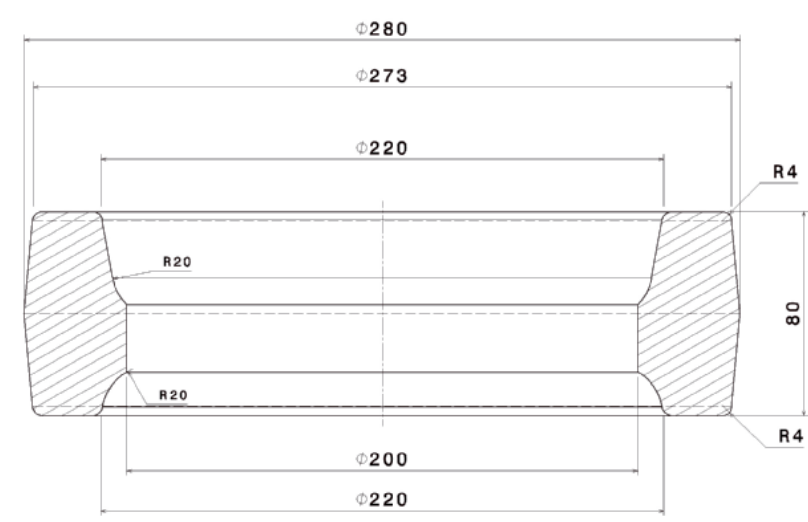

Fig. 1. Final geometry of the forging wheel.

scanner device. Then, each blow has been simulated using a thermo-elasto-viscoplastic model including damage and implemented by VUMAT user subroutine provided by $A B A Q U S$ software together with a $2 \mathrm{D}$ adaptive remeshing algorithm. The comparison between the digitised shape and the simulated shape enables the evaluation of parameters. Some corrections have been made about the friction parameter in order to improve the model.

The studied part is a forged wheel of a gearbox. The starting part is a cylinder of $42 \mathrm{CrMo} 4$ steel of $210 \mathrm{~mm}$ height $\left(h_{0}\right)$ and $130 \mathrm{~mm}$ diameter $\left(d_{0}\right)$. Dimensions of the final wheel are given in Figure 1. The Estamfor Company has designed the proposed forging process. Tools that are used for this process are a $100 \mathrm{~kJ}$ hammer and a mechanical press (max speed: $40 \mathrm{~mm} . \mathrm{s}^{-1}$ ).

The forging process is presented in Figure 2. It includes the following operations:

- The cylinder of steel is heated up to $1300^{\circ} \mathrm{C}$.

- A platting operation is performed with the hammer. It is composed of 3 blows (Figs. $2 \mathrm{a}-\mathrm{c}$ ).
- A forging operation is then started with the hammer with 5 blows (Figs. 2d-h).

- A blanking operation follows using the mechanical press blows (Fig. 2i).

- A deburring operation concludes the process also using the mechanical press (Fig. 2j).

\section{3D digitising}

Evolution of the shape is digitised using a 3D laser sensor scanner from Romer. It is a 2025 measuring arm with a GScan sensor shown in Figure 3. The 3D digitising operation has been performed in a room with controlled temperature and humidity to avoid change of dimensions. However, the 3D scanner includes a temperature sensor to provide auto corrected measurement.

The 3D scanner works according to the triangulation principle. A laser beam is changed into a plane with a prism. This plane makes a line when intersecting the part. Coordinates of 300 points are calculated on this line using a CCD camera. To obtain a complete point cloud that sample the entire surface of the part, the $3 \mathrm{D}$ digitising expert has to "sweep" the laser plane on whole part. The accuracy of our 3D scanner is of $0.3 \mathrm{~mm}$. Generalities about 3D digitising, including principle and causes of inaccuracy can be found in [18]. Because of the inaccuracy of a forging process like the one we study in this paper, the accuracy of our 3D scanner is enough to fit the parameters of our FEM simulation model.

For each part, we have obtained a $3 \mathrm{D}$ point cloud (Fig. 4a). Using the RAPIDFORM XOR software application, we have created a mesh from all these $3 \mathrm{D}$ point cloud (Fig. 4b). In the following sections of this paper, we call this mesh the real mesh.

Still using RAPIDFORM XOR software application, we can fit the real mesh and the result of our FEM simulation model (as an IGS file) with a least mean square algorithm (Fig. 4c).

Later in this paper, the comparison between experimental and numerical results is proposed. The comparison itself is performed with the CATIA V5 software application.

\section{Numerical simulation}

A special numerical methodology, currently developed by the LASMIS laboratory, has been used to perform the numerical simulation of various forging operations. This methodology uses several numerical tools including ABAQUS ${ }^{\circledR}$ FEM software with our thermo-elastoviscoplastic constitutive equation with ductile damage [7, $10,11,14,16]$. A fully adaptive numerical methodology is used, which combines the ABAQUS/Explicit with our house remeshing procedure. The dynamic explicit global resolution scheme is used to solve the equilibrium problem. 


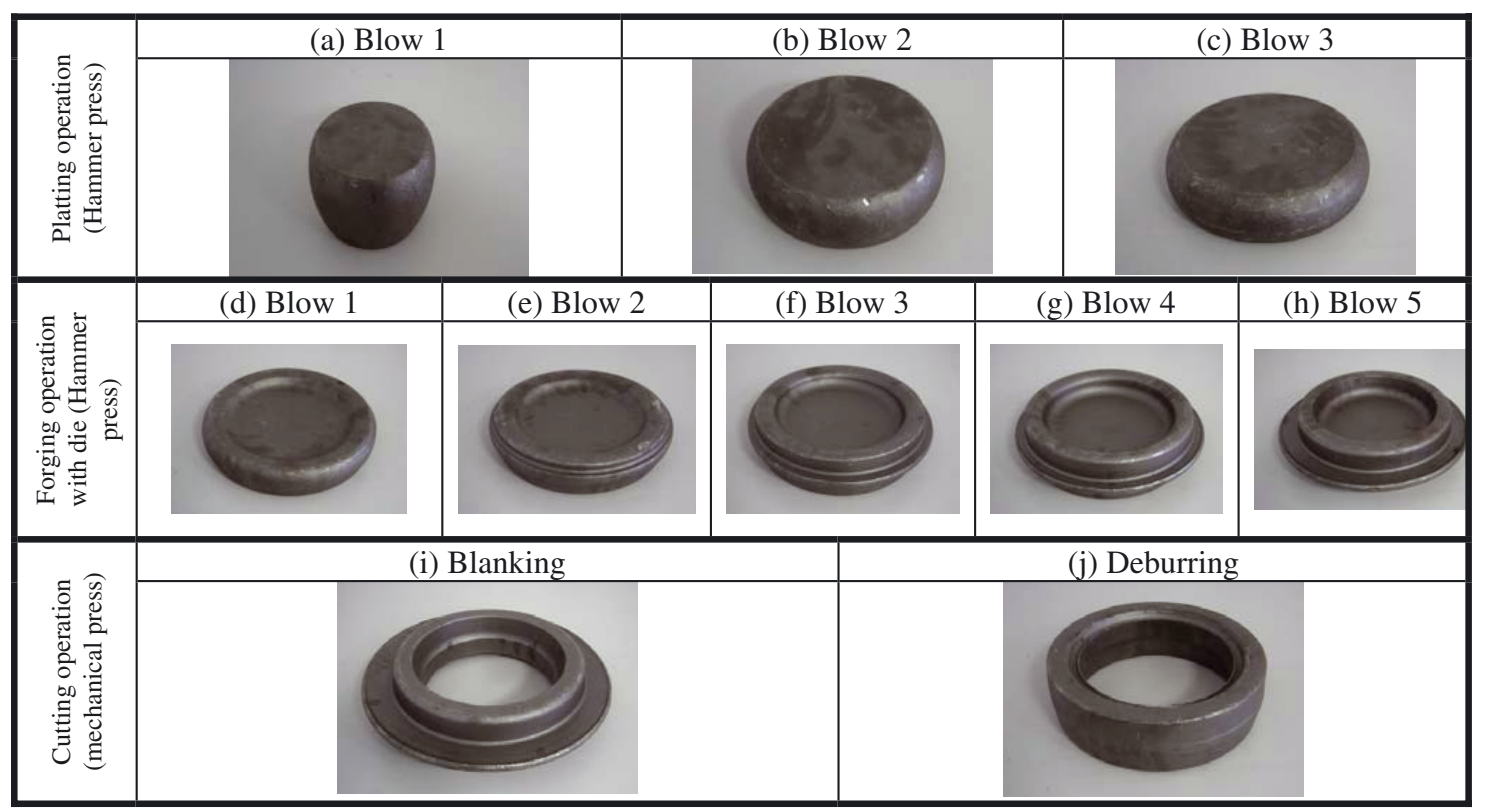

Fig. 2. Evolution of the forging part for different operations and blows.

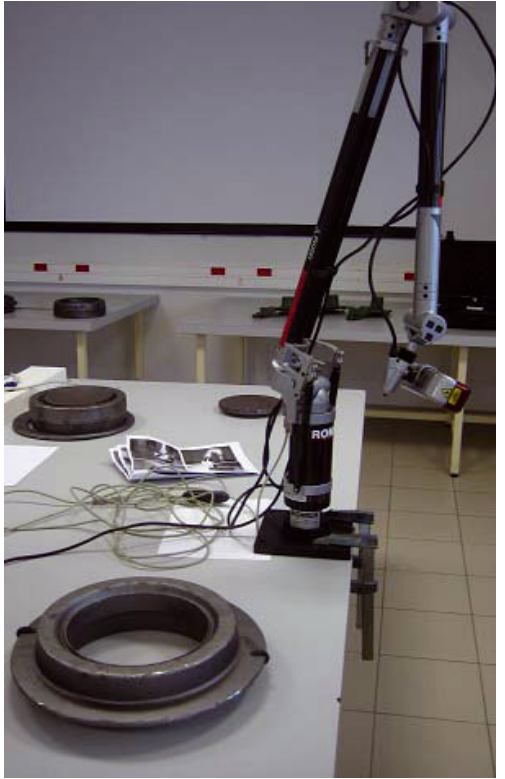

Fig. 3. Romer measurement equipment with G-scan laser scan.

\subsection{Thermo-elasto-viscoplastic constitutive equations}

A finite isotropic thermo-elasto-viscoplastic constitutive set of equations fully coupled with the isotropic ductile damage is developed using the classical thermodynamics of irreversible processes with state variables [16]. Four couples of internal state variables are used for this isothermal case: $\left(\underline{\varepsilon^{\mathrm{e}}}, \underline{\sigma}\right)$ for plastic flow, $(\underline{\alpha}, \underline{\mathrm{X}})$ for kinematic hardening, $(r, \bar{R})$ for isotropic hardening and $(D$, $Y$ ) for isotropic ductile damage.

When the current configuration contains some ductile damage, the concept of the effective state variables [16] based on the hypothesis of total energy equivalence is used to define the effective state variables. These are used in the state and dissipation potentials in order to derive the complete set of fully coupled constitutive equations for metal forming processes.

$$
\begin{aligned}
& \text { State relations: } \\
& \qquad \begin{aligned}
\underline{\sigma}= & (1-D) \underline{\underline{\Lambda}}(T): \underline{\varepsilon}^{e} \\
\underline{X}= & \frac{2}{3}(1-D) C(T) \underline{\alpha} \\
R= & \left(1-D^{\omega}\right) Q(T) r \\
Y= & \frac{(1+\nu)\left[\left(\left\langle\sigma_{\mathrm{I}}\right\rangle_{+}^{2}+\left\langle\sigma_{\mathrm{II}}\right\rangle_{+}^{2}+\left\langle\sigma_{\mathrm{III}}\right\rangle_{+}^{2}\right)\right]}{2(1-D) E(T)} \\
& -\frac{9 \nu\left[\left\langle\sigma_{\mathrm{H}}\right\rangle_{+}^{2}\right]}{2(1-D) E(T)}+\frac{1}{3} C(T) \underline{\alpha}: \underline{\alpha} \\
& +\frac{1}{2} \omega D^{\omega-1} Q(T) r^{2}
\end{aligned}
\end{aligned}
$$

where $\underline{\underline{\Lambda}}=2 \mu_{\mathrm{e}} \underline{\underline{1}}+\lambda_{\mathrm{e}} \underline{1} \otimes \underline{1}$ is the fourth order symmetric elastic properties tensor of the isotropic material; $C$ is the kinematic hardening modulus and $Q$ is the isotropic hardening modulus. $\langle x\rangle_{+}=\frac{x+|x|}{2}$ is the positive part of $x$.

Accounting for the softening effect due to dynamic recrystallization, a new couple variable $\left(r_{\mathrm{c}}, R_{\mathrm{c}}\right)$ was added. $Q_{\mathrm{c}}$ is the module associated with the effect of dynamic recrystallization, $r_{0}$ is a threshold strain and $b_{\mathrm{c}}$ the nonlinearity of evolution:

$$
R_{\mathrm{c}}=-\left(1-D^{\omega}\right) Q_{\mathrm{c}}(T)\left\langle r_{\mathrm{c}}-r_{0}\right\rangle
$$




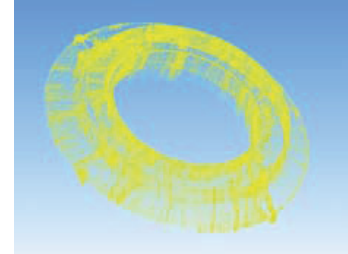

a)

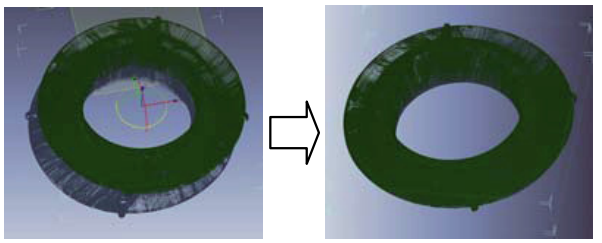

b)

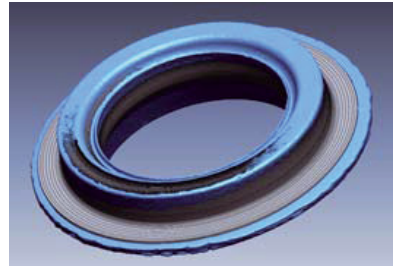

c)

Fig. 4. Point cloud of upper billet face, (b) mapping of the two upper mesh, (c) alignment of the experimental and numerical topology.

Evolution equations:

$$
\begin{aligned}
\underline{D}_{p} & =\dot{\delta} \underline{n} \\
\dot{\alpha} & =\dot{\delta}(\underline{n}-a \underline{\alpha}) \\
\dot{r} & =\dot{\delta}\left(\frac{1}{\sqrt{1-D^{\omega}}}-b r\right) \\
\dot{r}_{\mathrm{c}} & =\dot{\delta}\left(\frac{1}{\sqrt{1-D^{\omega}}}-b_{\mathrm{c}} r_{\mathrm{c}}\right) \\
\dot{D} & =\left(\frac{\left\langle Y-Y_{0}\right\rangle}{S}\right)^{s} \frac{\dot{\delta}}{(1-D)^{\beta}}
\end{aligned}
$$

where $a$ and $b$ characterize the non-linearity of the kinematic and isotropic hardening respectively; $Y_{0}$ (threshold), $S, s, \beta$ characterize the ductile damage evolution.

The deviatoric second order tensor $\underline{n}$ is the outward normal to the yield surface $f$ with damage effect defined by:

$$
f=\frac{J_{2}(\underline{\sigma}-\underline{X})}{\sqrt{1-D}}-\frac{\left(R+R_{\mathrm{c}}\right)}{\sqrt{1-D^{\omega}}}-\sigma_{y}(T)
$$

The scalar $\dot{\delta}$ is the viscoplastic "multiplier" solution of a Norton-Hoff viscoplastic potential:

$$
\dot{\delta}=\left\langle\frac{f}{K_{v}(T)}\right\rangle^{n_{v}}
$$

All the parameters $P \in\left[E, Q, Q_{c}, C, S, K_{v}, \sigma_{y}\right]$ are function of the temperature according to:

$$
P_{i}(T)=P_{0} \mathrm{e}^{-\alpha_{i} T}
$$

where $P_{0}$ is the value of the parameter at the room temperature and $\alpha_{i}$ is a thermal material parameter.

The global resolution scheme is dynamic explicit and it is associated with an automatic time step control. The computation of the stress tensor as well as the state variables is worked out by numerical integration of the fully coupled damage/thermo-elasto-viscoplasticity equations. The so-called elastic prediction - plastic correction methodology is used together with radial return mapping algorithm with an operator splitting methodology. An elimination procedure allows reducing the number of constitutive $[7,16]$.

\subsection{Adaptive FEM methodology}

A 2D adaptive FEM methodology has been developed to avoid the mesh distortion on a deformed geometry [10]. Indeed, in numerical simulations of forming processes, frequent remeshing is needed during the calculation to avoid strong mesh distortions caused by nonlinearities and especially to fit the size of the mesh to the nature of the problem solution $[1,4,15]$. Remeshing is essential in order to perform the calculations until the end of the process and obtain a correct solution enabling the removing of the total damaged elements. Furthermore, in addition to the physical aspects of the problem, the contact between the billet and tools requires locally a mesh refinement. Some specific error-indicators based not only on the gradient of physical fields (plasticity, temperature, damage, ...) but also on geometrical considerations related to such curvature of the billet and tools are also used. This 2D adaptive FEM methodology optimizes the number element in refining the active zones (high yielding, damage, ...) and coarsening inactive areas in order to keep nearly constant the number of degrees of freedom.

\subsection{Numerical simulation of the platting operation}

The billet is discretized with an axisymmetric CAX4RT. The size of the elements changes during the simulation, the maximum mesh size is $h_{\max }=6 \mathrm{~mm}$, within high plasticity area $h_{\text {min }}^{p}=1 \mathrm{~mm}$, and the zone with possible development of cracks $h_{\mathrm{min}}^{\mathrm{dam}}=0.1 \mathrm{~mm}$.

The material parameters for the 42CRMO4 steel have been determined by an inverse approach $[12,13]$. The numerical response equivalent von Mises stress - equivalent plastic strain has been plotted for different plastic strain rates $\dot{p}=\mathrm{d} p / \mathrm{d} t$ and different temperatures in Figure 5 . For high temperature $T=1300{ }^{\circ} \mathrm{C}$ and low plastic strain rate $\dot{p}=8 \mathrm{~s}^{-1}$, the accumulated plastic strain at fracture has a very large value of $1300 \%$.

An initial kinetic energy is imposed on the upper tool. The total falling mass (sum of the mass of the hammer and the tool) is 6.55 Tons. The initial velocity applied to the upper tool for the three blows is $V_{\mathrm{ini}}=5039 \mathrm{~mm} . \mathrm{s}^{-1}$.

The friction condition, heat generation by friction and heat exchange caused by contact between tools and billet are taken into account. The value of Coulomb friction coefficient is 0.2 . The conditions of heat flow convection with 


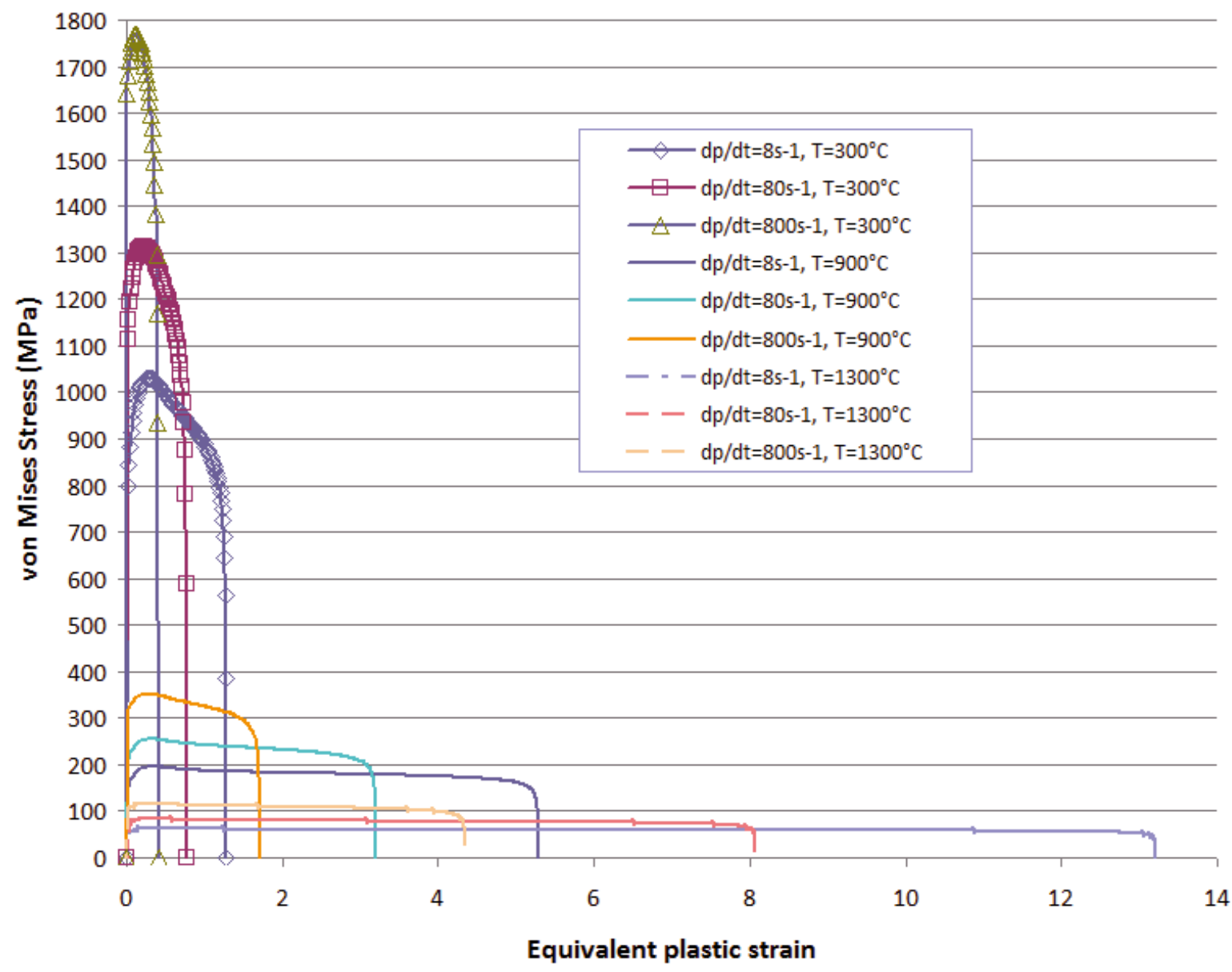

Fig. 5. Equivalent von Mises vs. equivalent plastic strain for different strain rates and temperatures.

ambient air and radiation are incorporated as boundary conditions on the outer surfaces of the billet.

The initial coarse mesh is refined in the areas where the plastic flow localizes. Figure 6 shows the evolution of the mesh, the isovalues of accumulated plastic strain and damage at the end of each blow. As expected, the mechanical fields (plastic strain, damage, ... ) localized along a crossed shear band. Maximum levels of damage are located in the center of the billet and the outer curved surface but with rather low values $D=0.04$. At the end of the platting operation, we obtain a plated billet with an upper diameter larger than the lower diameter. This asymmetry is due to the different effects of friction between the upper low plane surface and to the different strain rate inside the billet.

At the end of each blow, the outer contour of the mesh is used by a macro to generate a $3 \mathrm{D}$ CAD part from the Catia V5R19.

\section{Experimental and numerical comparison of geometrical topology of the forging part}

The experimental topologies (generated from the 3D point clouds) and numerical topologies (generated from the numerical mesh) are fitted using a least mean squares algorithm and compared according to the flowchart in Figure 7 . The objective is to correctly predict the final shape of the billet after each blow. The parameters of friction model were thus registered by successive iterations to converge to the experimental topology.

The results are presented in the Table $1, h_{0}$ is the initial billet height $(\mathrm{mm}), h$ is the height of the billet after the blow $(\mathrm{mm}), d_{h}$ is the diameter of the upper surface after blow $(\mathrm{mm}), d_{b}$ is the diameter of the lower surface after blow (mm).

For the first blow, the "curved flared" form observed on experimental geometry is almost respected by numerical geometry with a maximum deviation of $2 \mathrm{~mm}$. This form is due to the friction at the boundary conditions and the kinematics of the hammer. For the second blow, the differences between the experimental and numerical topologies do not exceed $1.5 \mathrm{~mm}$. And, for the final blow, the geometry error was below $1 \mathrm{~mm}$.

Then, we have extracted four $2 \mathrm{D}$ sections. These ones are colored in red, blue, green and brown in the scanned volume. The four $2 \mathrm{D}$ sections are compared with each others. We find that the forging billet is not exactly axisymmetric with maximum deviation of about $4 \mathrm{~mm}$. The 


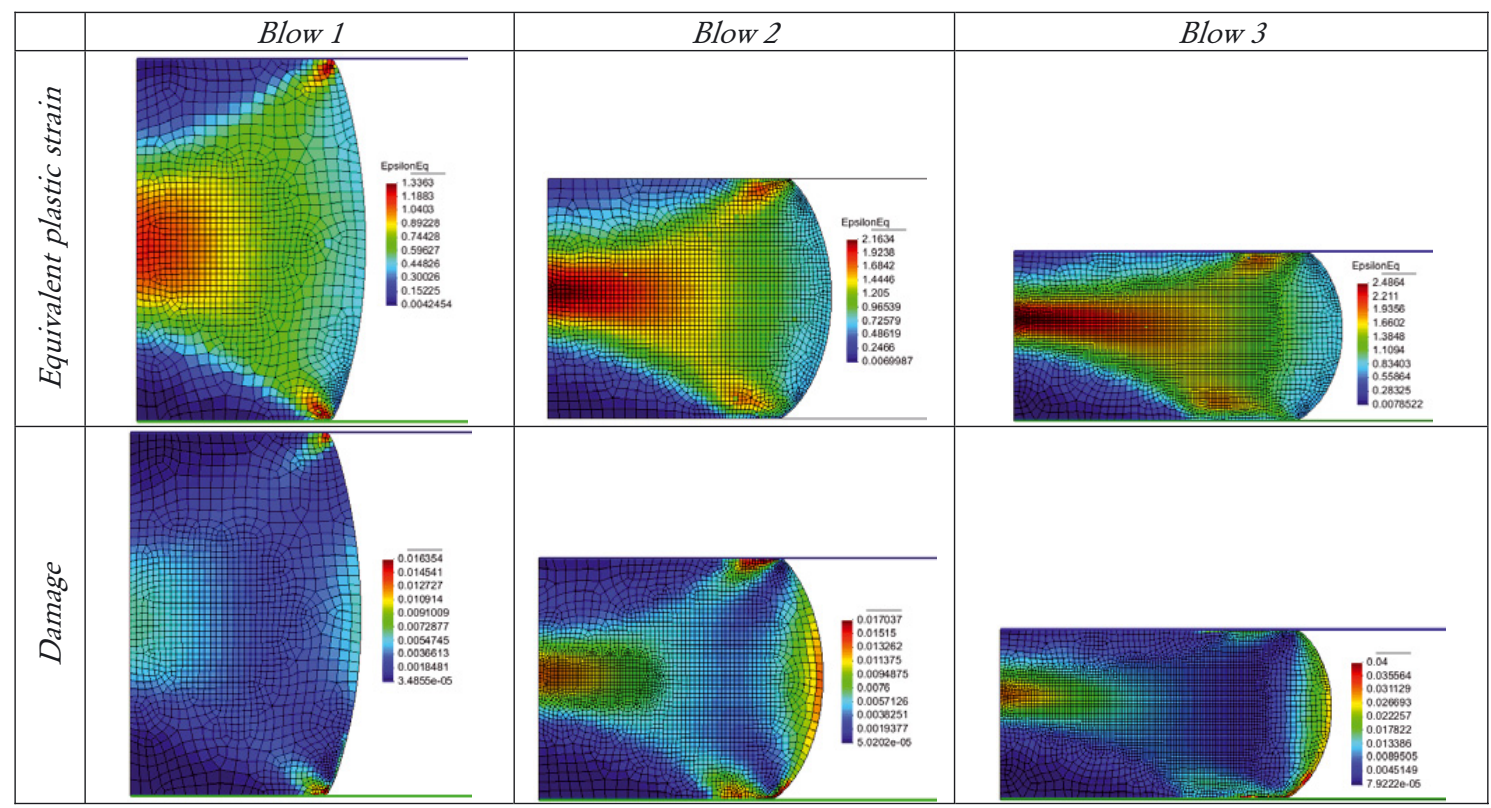

Fig. 6. Repartition of the equivalent plastic strain and damage at the end of each platting blow.

Table 1. Confrontation between experimental and numerical measurement.

\begin{tabular}{ccccccccccc}
\hline & \multicolumn{3}{c}{ Blow 1 } & \multicolumn{3}{c}{ Blow 2 } & \multicolumn{3}{c}{ Blow 3 } \\
\hline & $h_{0}$ & $h$ & $d_{h}$ & $d_{b}$ & $h$ & $d_{h}$ & $d_{b}$ & $h$ & $d_{h}$ & $d_{b}$ \\
\hline Simulation & 210 & 134.8 & 145.6 & 143.2 & 88.1 & 173.8 & 178.4 & 61.97 & 221 & 213.2 \\
Reality & 210 & 132.7 & 145.1 & 134.5 & 83.8 & 175.4 & 181.7 & 61.7 & 219.7 & 209.0 \\
Error \% & $0 \%$ & $1.6 \%$ & $0.3 \%$ & $6.5 \%$ & $3.8 \%$ & $0.9 \%$ & $1.8 \%$ & $0.4 \%$ & $0.6 \%$ & $2 . \%$ \\
\hline
\end{tabular}

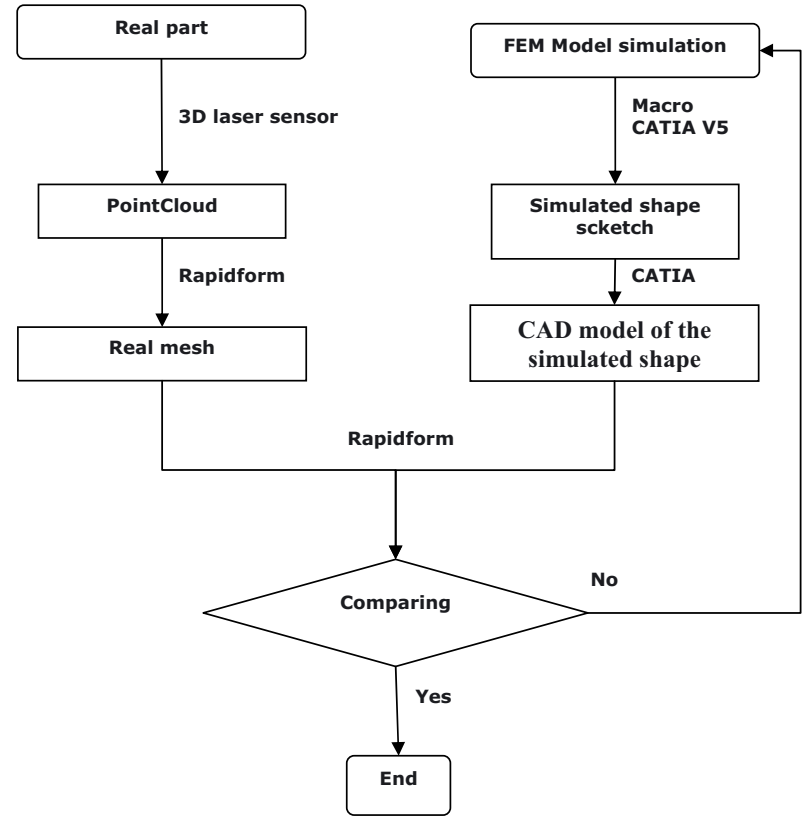

Fig. 7. Flowchart of the numerical and experimental topology comparison.

numerical predicted contour (black) is closed to the experimental contours with a maximum error of $4 \mathrm{~mm}$.
The numerical simulation seems accurate for the prediction of geometric form. Measures of residual stresses of the forged part and comparison with simulated stress tensor after springback should complete the analysis in the near future.

\section{Conclusion}

A benchmark of a forging process has been partially presented in this paper. The main advantage of the proposed approach is the knowledge about the geometry of the part after each strike. Comparison of this "real" geometry and the simulated one enables the improvement of the parameters of our simulation model. For example, we have deduced the value of the friction level from the successive geometry of the real parts.

All the data (CAD models of the tool and 3D point clouds from the digitising of the part about this benchmark are available on our website http://lasmis.utt. $\mathrm{fr} / \mathrm{fr} /$ index.html.

These experimental works have been done within the Manunet Pro-Eng project. This one is funded by OseoAnvar. Finally, we want to thank the Estamfor Company. This company has made the forging tools and all the forging process. 


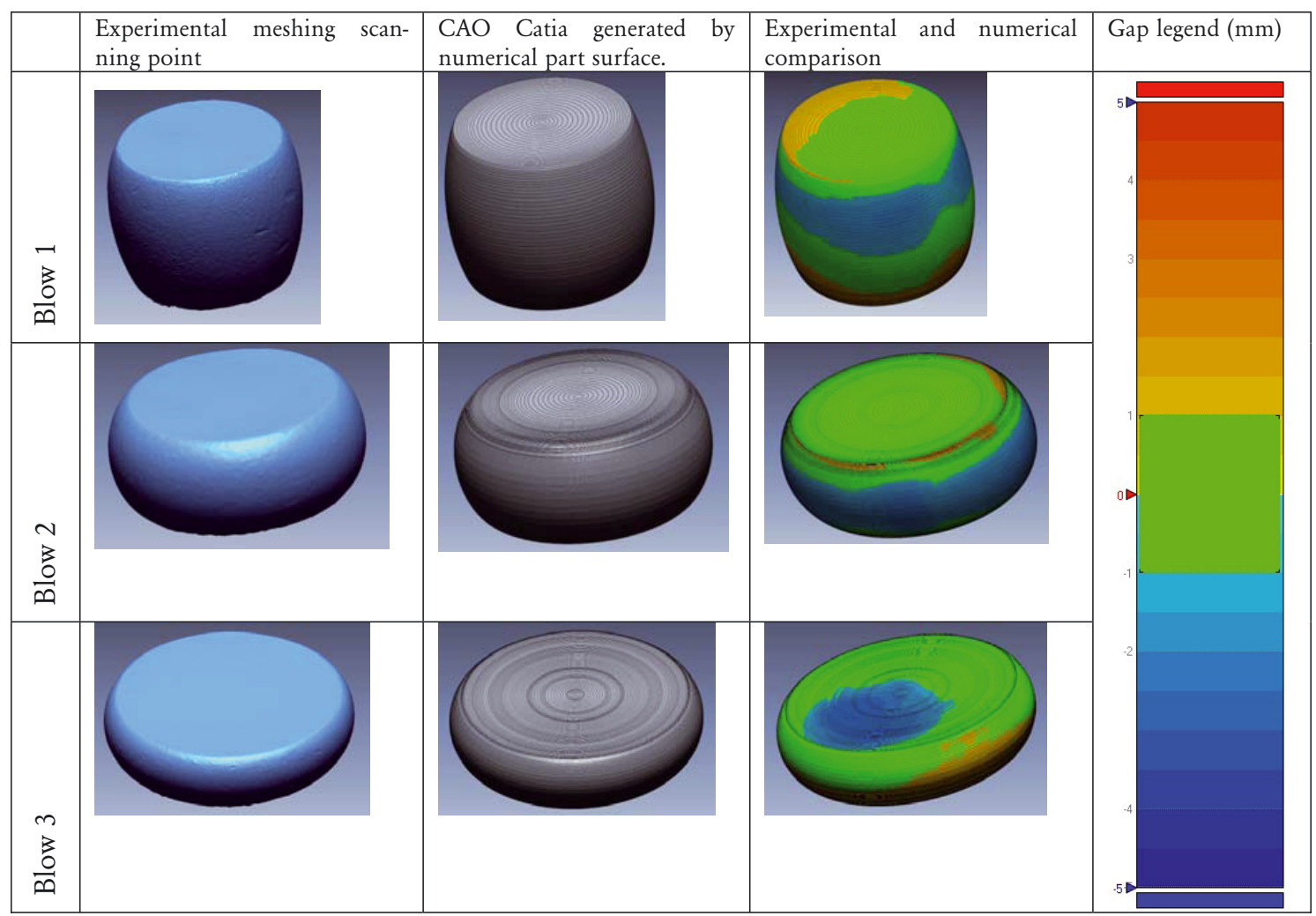

Fig. 8. Comparison of the experimental and numerical form of the billet for each blow.
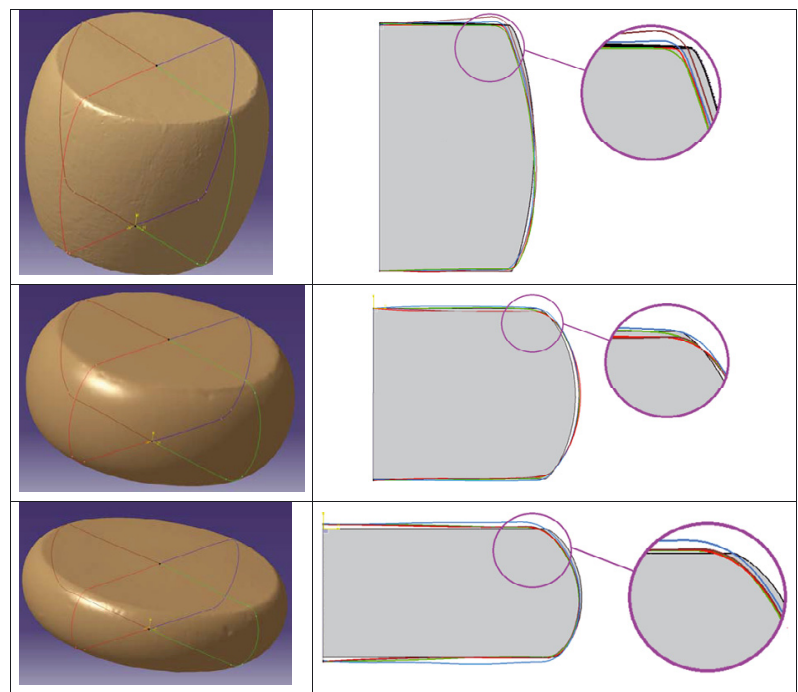

Fig. 9. Extraction of the 2D contours from volume and comparison

\section{References}

[1] F.M. Andrade Pires, J.M.A. César de Sá, L. Costa Sousa, R.M. Natal Jorge, Numerical modelling of ductile plastic damage in bulk metal forming, Int. J. Mech. Sci. 45 (2003) 273-294

[2] W. Bang, C.S. Lee, Y.W. Chang, Finite element analysis of hot forging with flow softening by dynamic recrystallisation, J. Mater. Process. Technol. 134 (2003) 153-158
[3] C.C. Chang, A.N. Bramley, Determination of the heat transfer coefficient at the workpiece-die interface for the forging process, J. Eng. Manuf. 216 (2002) 11979-21186

[4] T. Coupez, N. Soyris, J.-L. Chenot, Three-dimensional finite element modelling of the forging process with automatic re-meshing, J. Mater. Process. Technol. 27 (1991) 119-133

[5] P. Hartley, I. Pillinger, Development of computational modelling techniques for industrial metal forming processes, J. Eng. Manuf. 215 (2001) 903-914

[6] P. Hartley, I. Pillinger. Numerical simulation of the forging process, Comput. Methods Appl. Mech. Eng. 195 (2006) 6676-6690

[7] M. Issa M., K. Saanouni, C. Labergère, A. Rassineux, Prediction of serrated chip formation in orthogonal metal cutting by advanced adaptive 2D numerical methodology., Int. J. Mach. Mach. Mat. 9 (2011) 295-315

[8] Y.H. Kim, T.K. Ryou, H.J. Choi, B.B. Hwang, An analysis of the forging process for 6061 aluminium-alloy wheels, J. Mater. Process. Technol. 123 (2002) 270-276

[9] S. Kobayashi, S.-I. Oh, T. Altan, Metal Forming and the Finite Elements Methods, pages 1-6, Oxford University Press, New York, 1981

[10] C. Labergere, A. Rassineux, K. Saanouni, 2D adaptive mesh methodology for the simulation of metal forming processes with damage, 2011, DOI 10.1007/s12289-0101001-z, article in Press

[11] C. Labergere, P. Lestriez, K. Saanouni, Numerical design of extrusion process using finite thermoelastoviscoplasticity with damage, Prediction of chevron shaped cracks, KME 424 (2010) 265-272 
[12] Y.C. Lin, M.S. Chen, J. Zhong, Effects of deformation temperatures on stress/strain distribution and microstructural evolution of deformed 42CrM0 stell, Mater. Eng. 30 (2009) 908-913

[13] Y.C. Lin, M.S. Chen, J. Zhong, Prediction of $42 \mathrm{CrMo}$ steel flow stress at high temperature and strain rate, Mech. Res. Commun. 35 (2008) 142-150

[14] J. Mariage, K. Saanouni, P. Lestriez, A. Cherouat, Numerical simulation of ductile damage in metal forming processes, A simple predictive model, theoretical and numerical aspects, Int. J. Form. Process. 5 (2002) 363376

[15] K. Mocellin, L. Fourment, T. Coupez, J.L. Chenot, Toward large scale FE computation of hot forging process using iterative solvers, parallel computation and multigrid algorithms, Int. J. Numer. Methods Eng. 52 (2001) 473-488

[16] K. Saanouni, J.L. Chaboche, Application to Metal Forming, Computational Damage Mechanics, Numerical and Computational methods. in Comprehensive Structural Integrity, (ed.) I. Milne, R.O. Ritchie, B. Karihaloo, 3, 2003

[17] R.H. Wagoner, J.-L. Chenot, Metal forming analysis, Cambridge University Press, Cambridge, 2001

[18] W. Derigent, E. Chapotot, S. Remy, A. Bernard, G. Ris, 3D digitising strategy planning approach based on a CAD Model, J. Comput. Inf. Sci. Eng. 7 (2007) 10-19 